\title{
A cultura em debate: (des)encontros entre o marxismo e os estudos culturais
}

\author{
Giovani Ferreira Bezerra*
}

Palavras-chave:

Marxismo

Estudos Culturais

Pesquisa em Ciências Sociais

Keywords:

Marxism

Cultural Studies

Research in Social Sciences
Resumo: Este ensaio discute as implicações do conceito de cultura em duas grandes abordagens do conhecimento, que têm, direta ou indiretamente, influenciado e polarizado as pesquisas e discussões acadêmicas no século XX e no começo do século XXI, quais sejam as teorizações marxistas, herdeiras da racionalidade moderna, e os Estudos Culturais. Com essa discussão, intenta-se realizar um encontro possível entre as duas concepções, a fim de recuperar o equilíbrio na definição de cultura, para além dos reducionismos, das polarizações ou das generalizações presentes nessas teorizações. Ressalta-se que o ensaio não adota um enfoque antropológico stricto sensu, mas parte de formulações gerais dessas vertentes mencionadas. Ao final, apresenta-se o entendimento de cultura não apenas em sua dimensão simbólica, discursiva, subjetiva e subjetivante, mas também em sua dimensão material, econômica, política e social.

\begin{abstract}
This essay discusses the implications of the concept of culture into two major approaches to knowledge, they have, directly or indirectly, influenced and biased research and academic discussions in the twentieth century and early twentyfirst century, namely the theories Marxist, heirs of modern rationality, and cultural studies. Throughout this discussion, intends to carry out a possible meeting between the two concepts in order to restore balance in the definition of culture, in addition to reductionism, biases or gifts generalizations these theories. It is noteworthy that the test does not adopt an anthropological approach in the strict sense, but part of general formulations of these mentioned aspects. Finally, we present the culture of understanding not only in its symbolic dimension, discursive, subjective and subjectifying, but also in its material dimension, economic, political and social.
\end{abstract}

Recebido em 28 de junho de 2016. Aprovado em 06 de dezembro de 2016.
My face is coming I have to have it I am looking for the join I am loving my face so much my dark face is close to me I want to join [...].

Toni Morrison $\left(1987\right.$, p. 406) ${ }^{1}$.

\section{Introdução}

A definição e a abordagem científica da cultura, do ponto de vista dos primeiros estudos antropológicos, estiveram atreladas aos pressupostos do biologismo evolucionista dominante no século XIX, a partir de uma visão positivista de homem e sociedade. Naquele período, a nascente antropologia compreendia que todos os povos deveriam tender para o mesmo ideal de cultura ocidental europeia civilizada. Os povos que não se enquadravam nesse "estágio evolutivo" estariam em um nível inferior de desenvolvimento cultural, gerando uma abordagem comparativa, etnocêntrica e hierarquizante em relação às diferenças entre os povos e grupos humanos (CASTRO, 2009).

Não obstante, a noção primeira de cultura única, resultante de uma progressão linear $\mathrm{e}$ ascendente, tal qual defendida pelos evolucionistas, já era posta em xeque naquele mesmo século por AdolfBastian (1826-1905). Reagindoàs repercussões da biologia nas teorizações antropológicas da época, Bastian, que em 1886 tornou-se o primeiro diretor do Grande Museu de Etnologia de Berlim e, segundo relata Kuper (2002, p. 34), "[...] tentou demonstrar que, assim como as raças, as culturas são híbridas. Não existem culturas puras, distintas e permanentes.

\footnotetext{
* Professor Assistente II na Universidade Federal de Mato Grosso do Sul, campus de Naviraí (UFMS/CPNV) nos cursos de Pedagogia e Ciências Sociais. Mestre em Educação pela Universidade Estadual de Mato Grosso do Sul (UEMS). Doutorando em Educação pela Universidade Federal da Grande Dourados (UFGD). Linha de pesquisa: História da Educação, Memória e Sociedade. Líder do Grupo de Estudos e Pesquisas sobre Educação, Desenvolvimento Humano e Inclusão (GEPEDHI/UFMS/CNPq). E-mail: gfbezerra@gmail.com
} 
Toda cultura recorre a diversas fontes, depende de empréstimos e está em constante mudança”. Para Bastian, contudo, isso não excluía a existência de alguma universalidade e similaridade das práticas culturais humanas, porquanto, na acepção desse etnólogo,

Os seres humanos são bastante semelhantes, e toda cultura está enraizada numa mentalidade humana universal. As diferenças culturais eram causadas pelos desafios apresentados pelo ambiente natural local e pelos contatos entre as populações. O empréstimo era o mecanismo primário da mudança cultural. E como as mudanças culturais eram resultado de processos locais imprevistos - pressões ambientais, migrações, comércio consequentemente, a história não tem padrão fixo de desenvolvimento. (KUPER, 2002, p. 34, grifos meus).

Semelhante concepção inspirou o trabalho de Franz Boas (1858-1942), que fora aluno de Bastian. Boas lega importantes contribuições à pesquisa antropológica, sendo considerado um dos fundadores da moderna antropologia, que tem nele um dos maiores expoentes, no início do século XX. Sua noção de relatividade da cultura trouxe novas perspectivas para o debate em torno do tema, para além do determinismo biológico, do racismo e do eurocentrismo. Já Castro (2009, p. 18) ressalta que:

A concepção boasiana de cultura tem como fundamento um relativismo de fundo metodológico, baseado no reconhecimento de que cada indivíduo vê o mundo sob a perspectiva da cultura em que cresceu - em uma expressão que se tornou famosa, ele disse que estamos acorrentados aos "grilhões da tradição". O antropólogo deveria procurar sempre relativizar suas próprias noções, fruto da posição contingente da civilização ocidental e de seus valores.

A partir de então, de forma significativa no século XX, e adentrando o século XXI com notável repercussão, o conceito de cultura, cada vez mais ampliado e deslocado em relação aos interesses antropológicos iniciais, tem sido invocado em diversas situações e domínios do conhecimento. Vale ressaltar que não me é possível demarcar, por hora, todas as implicações desse conceito no campo da antropologia e seus desdobramentos nas diferentes gerações antropológicas. O que quero evidenciar, com este texto, é o entendimento de cultura de uma perspectiva mais generalizada, no campo das ciências sociais, sem me preocupar com as balizas de uma ou outra disciplina stricto sensu. Reservo esse debate mais especializado aos antropólogos de ofício. Ademais, se eu retomei algumas considerações quanto ao legado da antropologia, foi apenas para situar o leitor sobre as origens desse debate ao qual me proponho a realizar, sem a pretensão de historicizar o conceito de cultura na abordagem antropológica.

Tendo esclarecido esse ponto, é preciso destacar, desde meados do século XX, a irrupção de diversos movimentos sociais contestadores da chamada cultura dominante e a constituição identitária de grupos que reivindicam seu espaço na sociedade, muitos apresentando a ideia de uma cultura alternativa ou de uma contracultura. Por outro lado, defende-se cada vez mais que todos devem ter acesso à cultura e que esta é uma dimensão fundante da existência humana, ao mesmo tempo em que se liquefaz e se abstrai a noção mesma de cultura, tornando-se difícil precisá-la e conceituála, inclusive nos textos científicos e nos discursos acadêmicos. Assim, como um clichê ou um curinga, o uso conceito de cultura pode ser feito em vários contextos, sem uma reflexão radical sobre os seus sentidos e significados, tornando-o presa fácil de discursos viciados e esvaziados de conteúdo.

Nesse sentido, para além do uso pragmático e como chavão, ouso indagar sobre o que é, afinal, cultura, ou melhor, como se tem entendido e difundido esse termo na produção científica desde o século passado. Por certo, não me é possível, nos limites deste ensaio, empreender uma revisão exaustiva, compreendendo todas as perspectivas existentes e seus desdobramentos, mas tão somente apresentar reflexões e aproximações iniciais, de caráter geral. Por isso, opto por empreender uma discussão conceitual a partir de duas grandes abordagens do conhecimento, as quais têm, direta 
ou indiretamente, influenciado e polarizado as pesquisas no século XX e no começo do século XXI, quais sejam, as teorizações marxistas, herdeiras da racionalidade moderna, e os Estudos Culturais. Com essa discussão, busco, ao final, realizar um diálogo possível entre as duas concepções, a fim de recuperar o equilíbrio na definição de cultura, para além dos reducionismos ou generalizações presentes nessas teorizações. $\mathrm{Ou}$, como sinalizo na epígrafe deste trabalho, tento promover um encontro entre tais concepções, articulando-as em torno do mesmo objeto.

\section{Marxismo e cultura ${ }^{2}$}

Marx não se debruçou em estudos específicos sobre a cultura, até porque não era um culturalista, mas um filósofo materialista, e é nesse caminho que nos permite entender a cultura não como elemento autônomo da sociedade e do modo de produção correspondente, mas como um fenômeno da superestrutura, determinado, em última instância, pela base econômica e suas contradições de classe. Como citam Teixeira e Dias (2011, p. 125), “[...] a cultura no campo marxista aparece desde as elaborações de Marx e Engels, por mais que ambos não usassem esse termo ou tenham escrito tratados específicos sobre o tema". No livro A Ideologia Alemãa, concluído em 1846, Marx e Engels (2007) apresentam algumas considerações que indicam seu entendimento acerca da cultura, associada à esfera da produção, e não às relações meramente simbólicas ou a modos particulares de subjetivação.

Os autores entendem que a noção de cultura é perpassada e mesmo subordinada pela de classe, porquanto a classe dominante tende a controlar as ideias, as representações, as práticas sociais como um todo, levando a classe dominada a reproduzir as ideias, as convicções e os valores da classe dominante, sem grandes possibilidade de subversão dessa situação, a não ser pela via revolucionária propriamente dita. É nessa direção, segundo Trotski (1981 apud TEIXEIRA; DIAS, 2011, p. 131, grifos nossos), que:

\begin{abstract}
Como não se trata do homem considerado individualmente, mas o homem considerado socialmente, como a cultura é um fenômeno sóciohistórico pela natureza, e como a sociedade histórica tem sido e continua a ser uma sociedade de classes, a cultura acabou se tornando o instrumento fundamental da opressão de classe.
\end{abstract}

Em uma direção complementar, o marxista Lukács (1978) entende que, no bojo das relações sociais de produção capitalistas, a cultura tem se reduzido também à mercadoria, realçando a explicação economicista para a dimensão cultural da existência humana. Na perspectiva do autor, devido às condições econômicas antagônicas, em que o capital tornou-se um fim em si mesmo, subjugando todas as demais atividades humanasà relação de troca e de mercado, as realizações culturais desaparecem como tais, perdem seu sentido humanizador e sua autonomia, posto não valerem mais por si mesmas, mas assumirem, também, o caráter fetichizado de mercadoria. Lukács (1978, [s. p.]) traça, ainda, uma relação íntima entre cultura e modo de produção em um determinado contexto, afirmando que: "Efetivamente, se nós compreendemos corretamente a cultura de uma época, compreendemos em suas raízes o desenvolvimento do conjunto dessa época, como se tivéssemos partido da análise de suas relações econômicas". Dito de outro modo, a cultura não é, portanto, autônoma em relação à sociedade pautada pela lógica de mercado, mas se (con)funde à vida econômica.

Com o marxista italiano Antonio Gramsci, o conceito de cultura apresenta algumas inovações e desloca-se, paulatinamente, do campo estritamente econômico para as relações políticas que envolvem a luta por hegemonia na sociedade de classes. Gramsci dá lugar às classes subalternas e ao seu folclore, isto é, destaca as elaborações culturais presentes na linguagem e na "[...] religião popular e, consequentemente, em todo o sistema de crenças, superstições, opiniões, modos de ver e de agir que se manifestam naquilo que se conhece geralmente por 'folclore"' (GRAMSCI, 1995, p. 11). Nessa análise, o autor atenta para a necessidade de que 
os grupos dominados criassem e organizassem uma cultura contra-hegemônica, a qual superasse o senso comum em direção à consciência filosófica.

A cultura, portanto, torna-se palco de disputa política, de militância e de organização revolucionária, cabendo aos subalternos apropriarem-se coletivamente dos saberes da cultura burguesa que lhe fossem necessários para a constituição da hegemonia proletária. Por isso, afirma o filósofo que "Criar uma nova cultura não significa apenas fazer individualmente descobertas 'originais'; significa também, e sobretudo, difundir criticamente verdades já descobertas, 'socializá-las' por assim dizer" (GRAMSCI, 1995, p. 13). Essas verdades, isto é, essas formas de conhecimento e concepções de mundo deveriam ser criticadas e reelaboradas para que, a serviço dos interesses populares, fossem transformadas, nos dizeres do autor, "[...] em base de ações vitais, em elemento de coordenação de ordem intelectual e moral" (GRAMSCI, 1995, p. 13).

Tal processo de construção de uma cultura das classes trabalhadoras encontra sustentação, para Gramsci, no próprio trabalho como princípio educativo orgânico da escola unitária. Com base nesse princípio, o filósofo italiano entende que a transformação política e social se daria pela escola unitária como espaço privilegiado de (re)elaboração cultural para a constituição da hegemonia e da consciência crítica das classes subalternas, porque a ação política revolucionária implica, organicamente, a ação educativa (GRAMSCI, 1982). Para o autor (1982, p. 125), "O advento da escola unitária significa o início de novas relações entre trabalho intelectual e trabalho industrial não apenas na escola, mas em toda a vida social." Assim, Gramsci (1982, p. 125) prossegue, afirmando que: "O princípio unitário, por isso, refletir-se-á em todos os organismos de cultura, transformando-os e emprestando-lhes um novo conteúdo", qual seja, um conteúdo revolucionária de elevação cultural das massas, no sentido de torná-las dirigentes $d a$ e na práxis sócio-histórica.

Já a partir da Escola de Frankfurt, que retoma, atualiza e amplia proposições marxianas e marxistas, surgem críticas à cultura entendida enquanto produção massificada, reificada e industrializada. Adorno e Horkheimer (2006), expoentes da escola citada, citam que: "Sob o poder do monopólio, toda cultura de massas é idêntica [...]" (p. 100), e que, nessa ordem das ideias, "o mundo inteiro é forçado a passar pelo filtro da indústria cultural” (p. 104). É possível argumentar que, mediante a crítica frankfurtiana, a cultura é também entendida na acepção de fetiche - o que recupera a perspectiva lukácsiana - porquanto se torna mais uma mercadoria e, consequentemente, separa-se de seus produtores, aliena-se dos próprios homens como sujeitos históricos, coisifica-se e mistifica-se. A esse respeito, Ortiz (1985, [s. p.]), citando um trabalho de Adorno, afirma que:

$\mathrm{O}$ artigo "O fetichismo na música como regressão da audição", escrito em 1938, representa um marco para o tipo de análise elaborada pela Escola [de Frankfurt]. Nele, Adorno desenvolve de maneira sistemática a relação entre cultura e mercadoria. Retomando a noção de fetichismo trabalhada por Lukács, ele procura compreender como a cultura, de valor de uso, se transforma em valor de troca.

Mais recentemente, Eric Hobsbawm (2013), fazendo um balanço da cultura e da sociedade no século XX, traz importantes reflexões sobre o conceito em tela, à luz dos acontecimentos mais contemporâneos. O historiador realça as relações existentes entre política, cultura e o mercado no "breve século XX", para usar sua expressão consagrada. $\mathrm{Na}$ análise do célebre historiador, destaca-se o caráter contraditório que envolve a cultura na contemporaneidade, pois:

Como é, então, que a cultura, a política e o mercado interagem? Até agora, no que se refere aos estrategistas políticos, ao menos nos países democráticos, a cultura simplesmente não tem grande importância nas questões de política interna, como bem o demonstra o valor gasto pelo governo federal dos Estados Unidos nas artes e humanidades, em comparação com o valor gasto nas ciências. Internacionalmente, porém, a cultura pode ser assunto sério, sobretudo 
quando se torna símbolo de identidade nacional ou estatal [...]. (HOBSBAWM, 2013 , p. 43, grifos meus).

Entende-se, pelo fragmento supracitado, que a cultura é cada vez mais vista pela tensão viva entre a esfera local ou nacional e a esfera global ou internacional - entre nações - assumindo papel subordinado no primeiro caso e de destaque no segundo. Na geopolítica mundial, a cultura se constitui na forma de uma nação exercer hegemonia sobre outra, diante do avanço das políticas (neo)imperialistas, que estabelecem formas mais sutis de colonização. Sendo assim, a cultura emerge também como forma de se garantir alguma particularidade identitária aos Estados nacionais, estes cada vez mais soterrados pela globalização hodierna. Hobsbawm (2013) não deixa de perceber, ainda, o crescente caráter de mercado e de mercadoria impingido à cultura nas últimas décadas, dialogando, implicitamente, com a tradição frankfurtiana, ao reconhecer que tal tendência se intensifica e se universaliza com a globalização recente. Logo, o sentido artístico fica, por assim dizer, completamente subsumido ao retorno financeiro que pode ou não advir das produções artísticas, as quais se convertem em mais um negócio como outro qualquer, administradas por grandes empresas e corporações financeiras que visam ao lucro. $\mathrm{O}$ autor lembra que:

Do ponto de vista do mercado, a única cultura interessante é o produto ou serviço que dá dinheiro. Mas não sejamos anacrônicos. Nos campos culturais, o conceito contemporâneo de "mercado" - a busca indiscriminada, globalizante, do máximo de lucro - é bastante novo. Até poucas décadas atrás, as artes, mesmo para aqueles que lucram com elas, como investidores ou empresários, não eram como outros produtos. Não se negociava com arte, não se publicavam livros, não se financiavam novas peças nem se organizava a turnê internacional de uma grande orquestra por se achar que seria mais rentável do que vender lingerie [...]. Mais ainda, o conceito de uma única taxa universal de lucro à qual toda empresa deve se acomodar é produto recente do livre mercado globalizado, assim como o conceito de que a única alternativa para fechar o negócio é o crescimento ilimitado. (HOBSBAWN, 2013, p. 44, grifos meus).

Diante do exposto, percebe-se que o conceito de cultura, no âmbito do marxismo, também não é uniforme, até porque se pode falar em marxismos $^{3}$, e tem assumido sentidos e significados ligeiramente distintos, ao longo do tempo e de acordo com a escola ou autor que o adota. Se para Marx e Engels cultura seria basicamente um reflexo ou uma derivação da estrutura econômica ou base material, para Gramsci denota-se o caráter de disputa e de luta agonística por hegemonia que envolve a sociedade enquanto um bloco históricocultural. Já para os frankfurtinianos aparece como significativo o aspecto mercantil, massificado e massificador da cultura industrializada, objeto de consumo fetichizado e não emancipador. Cultura essa que segue do século XX para o século XXI ainda mais "fraturada" e mercantilizada, sob os desígnios do mercado mundial, como sugerem as últimas discussões empreendidas por Hobsbawm (2013). Mas, para além da crítica marxista, o que se entende por cultura em outros domínios teóricos? Para ser mais exato, o que os Estudos Culturais pensam sobre o assunto e trazem de inovador, a fim de se pensar algum diálogo e encontro entre essas abordagens? É este, portanto, o escopo do tópico seguinte, que constitui o segundo movimento deste texto.

\section{A virada cultural}

Nesta seção, trago algumas considerações a respeito da cultura tomando por base os Estudos Culturais, que empreenderam e empreendem uma reação ao marxismo clássico, ao promoverem uma virada cultural, de modo a evidenciar a centralidade substantiva e epistemológica da cultura na explicação das práticas sociais (HALL, 1997). Tal processo tem se desenrolado a partir da segunda metade do século XX como uma revolução paradigmática. $\mathrm{O}$ autor jamaicano assegura que: 
[...] uma revolução conceitual de peso está ocorrendo nas ciências humanas e sociais. Isso vai muito além da aprendizagem que nos leva a pôr as questões culturais numa posição mais central, ao lado dos processos econômicos, das instituições sociais e da produção de bens, da riqueza e de serviços - por mais importante que seja esta mudança. Refere-se a uma abordagem da análise social contemporânea que passou a ver a cultura como uma condição constitutiva da vida social, ao invés de uma variável dependente, provocando, assim, nos últimos anos, uma mudança de paradigma nas ciências sociais e nas humanidades que passou a ser conhecida como a "virada cultural". (HALL, 1997, p. 9, grifos meus).

Antes de se prosseguir na elucidação dessa virada, que introduz nas Ciências Humanas e Sociais uma revolução comparada à que Copérnico empreendeu na Astronomia, ao deslocar o centro explicativo do universo da Terra para o Sol, cabe explicar, em termos sintéticos, o que vem a ser o movimento dos Estudos Culturais e qual sua origem, movimento este que (re)colocou a cultura no centro do debate promovido pelas Ciências Humanas e Sociais, retirando-a da posição de subordinada, dependente, figurante e derivada que assumia outrora. A cultura se converte, então, em uma das atrizes principais do espetáculo humano. Deixa de ser meramente o cenário para ser ela mesma constituinte do enredo principal, agência e performance, linguagem $\mathrm{e}(\mathrm{m})$ ação, para usar aqui expressões de Homi Bhabha (1998): “[...] o teatro e a tela para a manifestação das capacidades da agência humana” (p. 263), “[...] funcionando no entretempo do signo/símbolo [...]" (p. 268). Em outras palavras, a cultura assume importância explicativa e estatuto teórico-epistemológico autônomo tanto quanto ou mais do que as relações econômicas da vida material e produtiva das sociedades, pois

[...] os processos econômicos e sociais, por dependerem do significado e terem consequências em nossa maneira de viver, em razão daquilo que somos nossas identidades - e dada a "forma como vivemos", também têm que ser compreendidos como práticas culturais, como práticas discursivas. (HALL, 1997, p. 10, grifo do autor).

Essa revolução cultural do nosso tempo, como caracteriza Stuart Hall (1997), surge no panorama político-ideológico e epistemológico que marcou o mundo logo após a Segunda Grande Guerra Mundial (1939-1945), em meados do século XX, como um campo de estudos interdisciplinares que parte da cultura como a referência precípua, na tentativa de superar o silêncio do marxismo ortodoxo em relação às questões culturais que tensionavam o mundo naquele período, enfrentando, assim, o reducionismo econômico que imperava na pesquisa sociológica e, ao mesmo tempo, evocando uma reação à barbárie do marxismo real. De fato, os pioneiros dos Estudos Culturais estavam ligados ao que se denominou como Nova Esquerda ${ }^{4}$, a qual empreendia críticas a algumas teses de Marx, vistas, então, como reducionistas, economicistas e vinculadas ao eurocentrismo (HALL, 1996). Conforme menciona Demetrio (2010, p. 3):

Nesse sentido, questionando o marxismo ortodoxo, os primeiros intelectuais dos estudos culturais iram se posicionar fundando uma relação constante e conflituosa com o marxismo. No entanto, essa relação foi fundamental para a transformação do conceito de cultura. Seja no sentido em que Raymond Williams operou, contribuindo para uma teoria materialista da cultura, o materialismo cultural, seja no sentido de Edward Thompson, para quem a ênfase na agência humana era determinante, a partir das experiências de homens e mulheres. O objetivo central desses intelectuais - reconhecidos como a nova esquerda britânica - era analisar o pensamento teórico marxista, tentando rever a questão do economicismo, de forma a incluir neste pensamento a preocupação com a questão da cultura.

Trata-se, porém, de um movimento intelectual não unívoco, que trabalha com temas de estudo, em vez de categorias, haja vista serem estas consideradas fixas ou (im)positivas demais para 
explicar a(s) realidade(s), surgido na Inglaterra dos anos de 1950 e oficialmente institucionalizado a partir dos anos de 1960, com a criação, em 1964, do Center for Contemporary Cultural Studies (Centro de Estudos Culturais Contemporâneos) na Universidade de Birmingham (HALL, 1997; COSTA; SILVEIRA; SOMMER, 2003). Os Estudos Culturais podem ser considerados como um projeto em construção, oposto às grandes narrativas e aos metadiscursos (HALL, 1996), estando "[...] Always open to that which it doesn't yet know, to that which it can't yet name" (HALL, 1996, p. 263 $3^{5}$ ). Ou, como caracterizam Costa, Silveira e Sommer (2003, p. 40), com base no texto de Heloisa Buarque de Holanda, trata-se de uma teoria viajante, pois apresenta “[...] uma vocação para transitar por variados universos simbólicos e culturais, por vários campos temáticos e teorias, encontrando portos de ancoragem onde se deixam ficar e começam a produzir novas problematizações". É por isso que esses mesmos autores ainda alegam que é:

[...] muito difícil, senão impossível, chegar-se a alguma precisão ou consenso relativamente a uma caracterização dos Estudos Culturais. Eles são muitas coisas ao mesmo tempo [grifos meus], tensionando os panoramas intelectuais e acadêmicos em que estão implicadas tanto as velhas e consagradas disciplinas como os movimentos políticos, práticas acadêmicas e modos de investigação tais como o marxismo, o pós-colonialismo, o feminismo, o pós-estruturalismo. Esse é o motivo pelo qual são frequentemente descritos como uma antidisciplina ou pós-disciplina. (COSTA; SILVEIRA; SOMMER, 2003, p. 43, grifo dos autores).

Todavia, é possível afirmar que, se há algum consenso entre os trabalhos resultantes da abordagem dos Estudos Culturais, é justamente o papel central que atribuem à cultura, por oposição (re)criativa à matriz marxista. Nesse sentido, rejeitase, no âmbito dos estudos culturais, a distinção clássica entre estrutura econômica e superestrutura, "[...] through which sophisticated and vulgar marxism alike had tried to think the relationships between society, economy, and culture (HALL, 1996, p. 265). Nessa perspectiva, a cultura é entendida como constituinte e constituída das e pelas relações sociais e econômicas, tornando-se uma instância de jogossimbólicos, disputas políticaspelo poder-saber, negociações, resistências, sobrevivências, tensões, formações discursivas, identidade(s) e hibridismos. Desaparece aqui a noção de cultura como mero reflexo imediato das estruturas econômicas ou da cultura monolítica, para se abrir espaço a outras formas de interpretar e significar o mundo, suas relações e as subjetividades, preferindo-se, por conseguinte, a noção de (inter)culturas, a fim de acentuar seu caráter híbrido, contingente e plural. Veiga-Neto (2003, p. 6, grifo do autor), ao discutir essa questão, com base em Hall, assevera que:

Assim, assiste-se hoje a uma verdadeira virada cultural, que pode ser resumida como o entendimento de que a cultura é central não porque ocupe um centro, uma posição única e privilegiada, mas porque perpassa tudo o que acontece na nossa vida e todas as representações que fazemos desses acontecimentos.

$\mathrm{Na}$ direção do exposto, Hall chama a atenção para o fato de que na contemporaneidade a explicação marxista e estruturalista de cultura estaria falida, porquanto incapaz de captar as novas demandas postas ao sujeito da pós-modernidade ${ }^{7}$ (HALL, 2005). As velhas oposições binárias de classe e a polaridade moderna entre cultura erudita e popular, cultura esclarecida e cultura de massa não conseguem captar os descentramentos, os deslocamentos e as desterritorializações do mundo pós-colonial e globalizado, com suas aporias, contingências e entre-lugares por onde passeia esse sujeito, que é múltiplo, polifônico e cambiante. Ninguém é apenas operário ou burguês. Cada pessoa participa ao mesmo tempo de uma rede de relações culturais e identitárias, toma lugar em diversas formações discursivas e assume várias identificações. A solidez conceitual da Modernidade ${ }^{8}$ e sua concepção aristocrática de cultura, assentada em (pro)posições enciclopédicas, como era a grande ambição do projeto Iluminista, é posta em xeque. As lutas deixam de ser compreendidas e empreendidas 
em seu aspecto físico-corporal para serem disputadas nos embates da textualidade simbólica, de maneira que a linguagem assume importância decisiva na forma de significar e constituir tais lutas, sendo ela própria um front de batalhas privilegiado, incorporando uma dimensão agonística. E, como diz Bhabha (1998, p. 263), nesse combate, "o agente [...] emerge no domínio social do discurso". Daí ser possível afirmar que:

Por bem ou por mal, a cultura é agora um dos elementos mais dinâmicos e mais imprevisíveis - da mudança histórica no novo milênio. Não deve nos surpreender, então, que as lutas pelo poder sejam, crescentemente, simbólicas e discursivas, ao invés de tomar, simplesmente, uma forma física e compulsiva, e que as próprias políticas assumam progressivamente a feição de uma 'política cultural' [...] (HALL, 1997, p. 04).

Assim, espero ter apresentando, ainda que de modo sumário, a compreensão de cultura que tem emanado dos Estudos Culturais nas últimas décadas, cuja história intelectual e institucional pode ser considera ainda bastante recente $\mathrm{e}$ promissora, o que não significa dizer que trabalhar com essa abordagem seja uma opção soft, como menciona Hall (1997). Tomar os Estudos Culturais como escolha paradigmática não é, como se tem por vezes alardeado, substituir uma explicação materialista por outra, idealista, mas, sobretudo, entender que, na produção do conhecimento científico, bem como nos espaços intervalares de embate entre hegemonias e reivindicações políticas conflitantes, a cultura não pode mais ser concebida e tematizada "[...] como uma variável sem importância, secundária ou dependente em relação ao que faz o mundo mover-se; tem de ser vista como algo fundamental, constitutivo, determinando tanto a forma como o caráter deste movimento, bem como a sua vida interior" (HALL, 1997, p. 6). É esse legado que torna atual e instigante visitar a agenda dos Estudos Culturais.

Não obstante, como mencionei na introdução deste ensaio, é possível recorrer às contribuições dessa perspectiva sem, necessariamente, abrir mão também das teorizações marxistas? Em outras palavras, pode-se conciliar ou ao menos (re)articular, de algum modo, ambas as abordagens para o entendimento da cultura, objeto de estudo neste ensaio e tema recorrente dos discursos hodiernos, exaustivamente repetido, porém quase nunca definido ou explicitado em relação à matriz teórica que o baliza? Dito de outro modo, conseguese superar certo pessimismo objetivado por Hall (1997, p. 265), quando este anuncia que: "There never was a prior moment when cultural studies and marxism represented a perfected theoretical fit"?? $\mathrm{Na}$ tentativa de fornecer pistas para uma primeira aproximação a tais questões, avanço para o tópico seguinte, apresentando algumas reflexões que sintetizam o terceiro movimento a ser empreendido neste texto, qual seja, a busca pelo encontro entre as duas grandes correntes teórico-epistemológicas supracitadas. A expectativa é romper com a lógica pautada apenas no confronto e na polaridade entre as teorias para assumir, em contrapartida, o diálogo e a negociação como princípios, com o intuito de "[...] articular elementos antagônicos e oposicionais sem a racionalidade redentora da superação dialética ou da transcendência" (BHABHA, 1998, p. 52).

\section{O encontro possível}

Antes de tecer as reflexões propriamente ditas sobre as possibilidades de encontro $\mathrm{e}$ articulação que vejo entre o Marxismo e o movimento dos Estudos Culturais, ambos delineados anteriormente, gostaria de chamar a atenção para o fato de que não promovo tal encontro na perspectiva da dialética materialista, que busca uma formulação qualitativamente superior em nova síntese depurativa, mantendo, porém, certa teleologia unidirecional e subordinação das antíteses ao crivo do pensamento e das categorias marxistas. Parece-me não ser o caso de utilizar esse caminho teórico-metodológico para cumprir o objetivo proposto, porquanto tal via apresentar-se reducionista e colonizadora sobre outras formas de elaboração teórica. 
Por isso mesmo, elegi a palavra encontro, como tenho reiterado neste ensaio. Quando duas ou mais pessoas se encontram, elas não se (con) fundem nem se anulam, não se tornam outra coisa transcendente e de qualidade supostamente mais elevada, por superar incorporando características positivas e negativas de teses opostas, como a dialética marxista supõe, mas estabelecem (inter) relações, dialogam, negociam sentidos, espaços, tempos de fala, complementam os discurso umas das outras, concordam, discordam e produzem consensos a partir de dissensos e vice-versa. Faço, portanto, essa ressalva para que não se espere um raciocínio segundo a lógica dialética consagrada pela tradição marxista, e sim no sentido dialético mais próximo ao que Bhabha (1998, p. 52) confere ao termo negociação. Como se posiciona o autor,

Quando falo de negociação em lugar de negação, quero transmitir uma temporalidade que torna possível conceber a articulação de elementos antagônicos ou contraditórios: uma dialética sem a emergência de uma História teleológica ou transcendente [grifos meus], situada além da forma prescritiva da leitura sintomática, em que os tiques nervosos à superfície da ideologia revelam a "contradição materialista real" que a História encarna. Em tal temporalidade discursiva, a evento da teoria torna-se a negociação de instâncias contraditórias e antagônicas, que abrem lugares e objetivos híbridos de luta e destroem as polaridades negativas entre o saber e seus objetos e entre a teoria e a razão prático-política. (BHABHA, 1998, p. 51, grifos do autor).

Tomando por base tais premissas, entendo que é necessário, nas Ciências Humanas e Sociais, empreender, finalmente, essa articulação não preconceituosa entre as formulações marxistas e culturalistas, a qual possibilite aos pesquisadores recorrer a ambas, sem ter de se enclausurar em uma ou outra matriz teórico-epistemológica, sem tornar-se presa fácil do sectarismo e proselitismo acadêmicos tão em voga, sem ter de fazer a falsa opção entre esta ou aquela para ser aceito na Academia. Dito de outro modo, gostaria que se abrisse espaço para o encontro e não para o confronto entre as abordagens, pois esse confronto é mais político e ideológico, na tentativa de preservar interesses corporativistas e resguardar posições intelectuais sectárias, do que epistemológico. Entendo que a ciência deva ser política, mas não partidária em sentido estrito, tampouco excludente, monológica e dicotômica. Por isso, empreendo o exercício de alinhavar o conceito de cultura a partir de abordagens consideradas opostas e, por vezes, rivais no cenário acadêmico atual.

Nessa perspectiva, depois de ter empreendido a revisão conceitual mencionada anteriormente, sou levado a compreender cultura não apenas em sua dimensão simbólica, discursiva, subjetiva e subjetivante, mas também em sua dimensão material, econômica, política e social. A cultura, no meu entender, encontra-se no intermezzo, é elemento de mediação entre as relações produtivas, materiais, e as representações, as ideologias, os símbolos, os discursos e as práticas sociais. Logo, o termo mediação rompe com a polaridade explicativa entre marxismo e culturalismo, estabelecendo uma vinculação orgânica entre ambos. Tal vinculação é o que precisa ser recuperado nas pesquisas da área a fim de se resgatar o equilíbrio conceitual e o significado do termo cultura, onipresente nas discussões hodiernas, mas tratado de modo superficial ou esquemático. Em vez de nos prendermos a escolas de pensamento, transformadas em prisões intelectuais que cerceiam nosso ser-fazer de pesquisadores, cumpre olhar para o objeto e identificar os apelos que este nos faz para sua inteligibilidade.

Não obstante, na contemporaneidade, chegamos ao extremo de escolher, primeiramente, uma filiação teórica e um conjunto de autores - e nesse aspecto gosto da analogia ao partido político -, para, depois, pensarmos no objeto de pesquisa e em suas possibilidades investigativas. Se o sujeito pertence a um grupo, não pode dialogar com outro. Está condenado a escrever e falar apenas o que seus autores de referência ou seus mestres e pares autorizam. Associo, também, esse processo à conversão religiosa, pois essa metáfora do convertido parece-me bastante sugestiva do 
que temos presenciado nas universidades e seus domínios. Ora, assim pouco se faz ciência, mas sim proselitismo e doutrinação.

Com essa breve digressão, quero explicitar que, se nos limitamos a uma ou outra abordagem fetichizando-a, para usar um termo marxista, podemos ficar cegos diante de questões relevantes para o avanço do conhecimento, posto que nenhuma teoria é autossuficiente, embora sejamos levados a crer que sim. Novamente, a metáfora da religião! $\mathrm{E}$ os autores que escolhemos cultuar ou que nos fizeram cultuar podem resolver todos os problemas que venham a aparecer em nossas pesquisas - isso quando são identificados como problemas - ou responder às novas questões postas pelas constantes transformações e lutas sociais. Ledo engano!

Vou, então, utilizar um exemplo para ressaltar meu posicionamento acerca da cultura como mediação e não como instância subordinada, passivamente determinada, nem como apoteose ou instância centralizada e centralizadora. $\mathrm{O}$ caso dos indígenas é emblemático do encontro que estou tentando promover, na condição de mediador. Se tomo a cultura indígena como foco de análise, não posso me furtar a compreender a exploração econômica a que esses povos têm sido submetidos pelo modo de produção capitalista desde os tempos da colonização portuguesa, sua expropriação e conversão histórica em lumpemproletariado, o uso mercantil dos artefatos de sua cultura material - que também perdem o valor em si para se convertem em valor de troca - o exotismo alienante disseminado pelo multiculturalismo burguês em relação às manifestações culturais indígenas, entre outros aspectos nos quais sobressai a determinação totalizante da economia, vale dizer, das relações sociais de produção inscritas no capitalismo e a hegemonia das classes dominantes sobre os "subalternos", entre os quais estão os índios.

Para o pensador marxista ortodoxo, contudo, aexplicaçãofecha-senessenívele,pormaispontosque se levante a ele, retoma invariavelmente às questões de classe e às consequências ontológicas do modo de produção. Ademais, o paradigma marxista, em suas manifestações mais conservadoras, comete um equívoco conceitual, ao identificar - ou pelo menos não se preocupar em distinguir suficientemente cultural e social, tratando-os quase como sinônimos. Essa identificação é a chave para entender - e superar - o reducionismo economicista que, por vezes, caracteriza os trabalhos sobre cultura nessa abordagem. A explicação apresentada pelo viés econômico não esgota, porém, o assunto. Afinal, como entender as especificidades antropológicas dos índios, suas formas de resistência, suas identidades e identificações, sua religião, seus costumes e seus problemas, os preconceitos e a violência que sofrem tanto por parte das classes dominantes como do mais pobre dos proletários, sem homogeneizá-los ou forçadamente subordiná-los a uma teleologia revolucionária e emancipadora da qual podem se recusar a pertencer ou com a qual não se identificam? É nesse ponto que os Estudos Culturais podem trazer contribuições ímpares para o entendimento da problemática lançada, ao trabalhar com noções de hibridismo e tradução cultural, diásporas, identidades descentradas, a agonística das relações culturais entre ex-colonizados e ex-colonizadores, hegemonia, alteridade (ou outridade), culturas de sobrevivência, entre outros.

À medida que a condição indígena possa ser vista pelo enfoque de ambas as correntes, sem a negação de uma pela outra, mas mediante a articulação, pode-se avançar no (re)conhecimento dos direitos, singularidades, valores, conflitos e necessidades dessa população, bem como evidenciar suas distâncias e proximidades aos esquemas interpretativos defendidos, quer seja pela tradição do materialismo histórico-dialético, quer seja pelos Estudos Culturais. Quando não admitimos, todavia, o diálogo entre as posições marxista e culturalista, muitas indagações sequer são postas ao pesquisador, ou continuam separadas, parcialmente respondidas, sempre desencontradas, incompletas e limitadas em seu potencial heurístico. Creio que esse é um passo fundamental para abrandarmos as posições reducionistas que apenas limitam nossa compreensão acerca da realidade e retardam o avanço das ciências do homem, as quais deveriam estar a seu favor e não contra; a serviço dele e não este subjugado por elas. 
Sendo assim, o estudioso das questões indígenas, se quer ter uma compreensão mais profunda do assunto, deverá considerar a cultura em sua multiplicidade significativa, como elo entre o que se passa na base material e as representações que os homens fazem de sua existência e de si próprios. Isto equivale a considerar que a cultura é material, imaterial, política e simbólica ao mesmo tempo; é produzida no embate e na luta de classes, mas é também produtora das próprias classes e de suas narrativas, pois a economia pode ser culturalmente forjada - lição esta já deixada por Weber (2004) - em vez de ser apenas uma forma apriorística de organização social da produção, da qual tudo deriva; por outro lado, a noção de classe é fixa demais para dar conta de todas as configurações e diferenças culturais, com suas contingências, sincretismos e ambivalências, o que demanda uma análise também sobre a identidade da cultura (BHABHA, 1998) e as culturas das identidades, com suas lutas políticas, seus sistemas de significados e modos de interpretar o real.

Recorri a esse exemplo para que melhor se pudesse vislumbrar o diálogo possível que proponho aqui, situando a cultura nesse espaço intervalar entre o econômico e o político, entre material e o simbólico, entre o produtivo e o discursivo, o modelar e o mimético. Afinal, a cultura é constitutiva e constituinte da sociedade, mas não é a sociedade em sentido estrito, não é uma estrutura fixa, nem uma essência superestrutural, porquanto preserva sua especificidade e variabilidade antropológica, podendo-se afirmar que é uma forma de interpretação do social, simultaneamente universal e particular, local e global, uma agência humana, um modo de relação entre os sujeitos que não se limita às relações de trabalho $\mathrm{e}$ produção ou de explorador e explorado, alienação e emancipação, mas que envolve temporalidade, poder, iteração, contestação, criação e reprodução, mito e razão, fronteiras móveis, constantemente (re)desenhadas. Essas ideias eu as tomo, como se percebe, dos Estudos Culturais para avançar em minhas reflexões.

Posso considerar, enfim, que o encontro entre essas abordagens não redunda em ecletismo ou confusão epistemológica, ao menos se somos honestos ao dizer quais conceitos utilizamos de uma ou outra concepção, por que o fazemos e em que medida elas se articulam ou se complementam, divergem ou convergem, distanciam ou se aproximam. Tal modo de construir textos tem sido preterido na Academia, em nome da preservação do status quo de determinadas teorias em detrimento de outras. Mas sempre foi esse o modo pelo qual a ciência vislumbrou seus maiores progressos. Marx não teria avançado em suas teorizações críticas sobre o modo de produção capitalista e sua necessidade de superação revolucionária caso não tivesse dialogado com as ideias liberais de Adam Smith, para citar um exemplo conhecido. Por outro lado, os Estudos Culturais não podem valer por si mesmos, isto é, não podem desconsiderar o fato de também estarmos imersos em uma sociedade que organiza a produção, a distribuição e o consumo dos bens materiais e culturais a partir da lógica excludente do capital, o que supõe certa economia das trocas culturais e uma cultura econômica fundante.

Todavia, como expus, essa cultura econômica capitalista não é a única, nem é autossuficiente para entender e explicar todos os fenômenos abrigados sob o signo da cultura. Esta também organiza e determina a produção, como evidencia o legado weberiano. Estudando a ética das religiões protestantes - e aqui estamos, portanto, nos domínios da cultura - como uma das propulsoras do capitalismo nascente, Weber (2004) tece uma reflexão que é fundamental para ilustrar o que pretendo explicar e evidenciar neste ensaio. $\mathrm{O}$ autor nos adverte que:

[...] embora o homem moderno, mesmo com a melhor das boas vontades, geralmente não seja capaz de imaginar o efetivo alcance da significação que os conteúdos de consciência religiosa tiveram para a conduta de vida, a cultura e o caráter de um povo, não cabe, contudo, evidentemente, a intenção de substituir uma interpretação causal unilateralmente "materialista" da cultura e da história por uma outra espiritualista, também ela unilateral. 
Ambas são igualmente possíveis, mas uma e outra, se tiverem a pretensão de ser, não a etapa preliminar, mas a conclusão da pesquisa, igualmente pouco servem à verdade histórica. (WEBER, 2004, p. 167, grifos da edição).

Ademais, a cultura não é unívoca, compreendendo uma textualidade enunciativa e literária que precisa ser interpretada além de categorias materialistas tradicionais, mas sem se abrir mão destas e sem tomá-las como conclusivas por si sós. Por isso, creio que semelhante articulação somente é plausível pela dialética do encontro, que não é a dialética do paradigma marxista, e sim a dialética que envolve a negociação de sentidos e significados, o diálogo, a intextualidade e o hibridismo fronteiriço entre as epistemologias. Para retomar a expressão poética de Toni Morrison (1987), trata-se, então, de procurar a junção, a união e a ligação entre as correntes teóricas - explorandose aqui o sentido mais profundo do vocábulo join - em vez da separação definitiva.

\section{Considerações finais}

$\mathrm{O}$ intuito que me moveu neste trabalho foi, portanto, a tentativa de significar cultura a partir das duas abordagens propostas, olhando uma com os olhos da outra e vice-versa, de modo a convergir o olhar para o mesmo objeto, ainda que as imagens captadas sejam distintas. Esse encontro, não nego, pode ser dramático, mas formativo e revigorante. Assim, espero ter lançado provocações inquietantes sobre o tema e realizado um exercício intelectual profícuo, diante do que convido os demais pesquisadores a (d)escreverem também tal movimento de descentramento quanto a suas posições teóricas mais inflexíveis, abrindo espaço para uma dialética do encontro, como aqui proposta.

\section{Notas}

1 Eis a tradução do fragmento supra na versão em português do livro citado: "Meu rosto está vindo tenho que tê-lo busco o encontro estou amando tanto o meu rosto meu rosto escuro está perto de mim quero o encontro" (MORRISON, 2007, p. 41).
2 Neste tópico, optei por não problematizar a concepção de cultura dos estudiosos (neo)marxistas ingleses, porque me reportei, sobretudo, ao marxismo mais conservador, dominante e/ou mais difundido, bem como porque os autores da corrente inglesa se aproximam, com mais propriedade, da discussão ora empreendida a partir dos Estudos Culturais, tendo dialogado com esse movimento e influenciado sua gênese. Destarte, vale a pena conferir, entre outros, o trabalho de Raymond Williams, que, ressignificando o campo marxista, desenvolveu o chamado materialismo cultural, muito promissor para se aprofundar as reflexões que ora tento suscitar (GLASER, 2008).

3 Certamente, neste texto, fiz uma abstração, deixando de lado várias facetas dessa vertente epistemológica, como o marxismo cultural inglês, por exemplo.

4 A Nova Esquerda - movimento político de esquerda atuante, a partir década de 1960, especialmente na GrãBretanha - influenciou a produção científica e o ativismo político de Hall. Trata-se de um movimento proveniente da tradição marxista, embora tenha questionado radicalmente a concepção ortodoxa e economicista do marxismo hegemônico, discutindo outros pontos de vista quanto à relação entre estrutura e superestrutura, inclusive no que tange ao entendimento acerca da cultura. Dados os limites deste texto e a especificidade teórica da Nova Esquerda, essa questão não será aprofundada neste texto, visto que busca uma discussão mais genérica. Não se podem desconsiderar, todavia, as inovações produzidas no interior desse movimento inglês, que possibilitaram enfatizar as questões culturais até então secundarizadas, destacando-se os trabalhos de Raymond Williams, Edward Thompson e Richard Hoggart.

5 "Sempre abertos àquilo que ainda não conhecem, ao que ainda não podem nomear" (tradução minha).

6 "[...] através da qual tanto o marxismo sofisticado como o vulgar tentaram pensar as relações entre sociedade, economia e cultura" (tradução minha).

7 Entende-se, neste texto, a partir de Hall (2005), que: "O sujeito pós-moderno assume diferentes identidades em diversos momentos, ou seja, no mesmo indivíduo coexistem identidades contraditórias que são impulsionadas em diversas direções, ocasionando contínuos deslocamentos. O conceito de sujeito integrado e estável se desfaz" (MORAES, 2009, p. 89). Vale ressaltar que esse conceito não é unívoco e absoluto, como não o é, aliás, o de pós-modernidade. Maciel-Lima e Souza-Lima (2010, p. 201), em artigo instigante, no qual problematizam esse conceito, alertam que: “[...] a despeito dos elementos constitutivos e constituintes, o sujeito pós-moderno continua uma incógnita", conforme visto por diferentes matizes teórico-interpretativas (MACIEL-LIMA; SOUZA-LIMA, 2010).

$8 \mathrm{O}$ conceito de modernidade não é unânime. Na acepção deste texto, endossa-se a perspectiva mais genérica de 
que "Podemos aqui compreender a modernidade como a época em que o homem, entendido como ser dotado de razão, passa a ser a medida de todas as coisas. A partir do seu advento, os fenômenos da natureza, a legitimidade da ordem social, do mundo humano, e os sentidos da história devem ser explicados à luz de princípios racionais e não míticos e religiosos. Cabe à razão dar conta de uma tarefa outrora atribuída ao mito, à religião e à metafísica clássica, a saber: assegurar a unidade e a estabilidade do mundo humano, fundamentar a ordem, buscar e garantir um sentido e uma verdade para a vida e a própria história humanas [...]. Esta crença na autoridade da razão está na base do Projeto Iluminista ou do Esclarecimento. Um movimento intelectual, filosófico, político, ideológico e cultural deflagrado no século XVIII, cujas premissas contribuíram para construção das grandes utopias emancipatórias modernas e que estiveram no centro das revoluções sociais e políticas desde os séculos XVIII e XIX, até o século passado [isto é, século XX], quer as de tradição liberal, quer as de tradição socialista" (BEZERRA, 2007, p. 181). Maiores detalhes sobre as diversas abordagens referentes aos conceitos de modernidade e pós-modernidade podem ser consultados em Bezerra (2007).

9 "Nunca houve um momento anterior em que os estudos culturais e o marxismo representassem um ajuste teórico perfeito" (tradução minha).

\section{Referências}

ADORNO, T. W.; HORKHEIMER, M. Dialética do Esclarecimento: fragmentos filosóficos. Rio de Janeiro: Jorge Zahar, 2009.

BEZERRA, T. C. E. Modernidade e PósModernidade: uma abordagem preliminar. Textos e Debates: revista de Ciências Humanas, Boa Vista, n. 13, p. 176-202, 2007. Disponível em: $<$ http://revista.ufrr.br/textosedebates/article/ view/892/737>. Acesso em: 2 dez. 2016.

BHABHA, H. K. O local da cultura. Belo Horizonte: UFMG, 1998.

CASTRO, C. Apresentação. In: BOAS, F. Antropologia Cultural. 5. ed. Rio de Janeiro: Jorge Zahar, 2009. p. 7-23.

COSTA, M. V.; SILVEIRA, R. H.; SOMMER, L. H. Estudos Culturais, Educação e Pedagogia. Revista Brasileira de Educação, Rio de Janeiro, n. 23, p. 36-61, maio-ago. 2003. Disponível em: <http:// www.scielo.br/pdf/rbedu/n23/n23a03.pdf >. Acesso em: 18 nov. 2014.

DEMETRIO, E. "Da Diáspora": a formação dos estudos culturais e o deslocamento da questão cultural. Cadernos Imbondeiro, João Pessoa, v. 1, n. 1, p. 1-6, 2010. Disponível em: <http:// periodicos.ufpb.br/ojs/index.php/ci/article/ view/13520/7679>. Acesso em: 2 dez. 2016.

GLASER, A. L. Materialismo Cultural. 2008. 236 f. Tese (Doutorado em Letras) - Programa de PósGraduação em Letras, Universidade de São Paulo, São Paulo, 2008. Disponível em: <http://www.teses. usp.br/teses/disponiveis/8/8147/tde-03082009151710/pt-br.php>. Acesso em: 2 dez. 2016.

GRAMSCI, A. Os intelectuais e a organização da cultura. 4. ed. Rio de Janeiro: Civilização Brasileira, 1982.

Concepção dialética da história. 10. ed. Rio de Janeiro: Civilização Brasileira, 1995.

HALL, S. A centralidade da cultura: notas sobre as revoluções culturais do nosso tempo. 1997. Disponível em: <http://www.gpef.fe.usp.br/teses/ agenda_2011_02.pdf>. Acesso em: 18 nov. 2014.

. Cultural studies and its theoretical legacies. In: MORLEY, D.; KUAN-HSING, C. (Ed.). Stuart Hall - critical dialogues in cultural studies. London; New York: Routledge, 1996. Disponível em: <https://www.amherst.edu/media/view/91999/ original/Hall\%2B-\%2BCultural\%2BStudies\%2Ban d\%2BIts\%2BTheoretical\%2BLegacies.pdf>. Acesso em: 18 nov. 2014.

A identidade cultural na pósmodernidade. 10. ed. Rio de Janeiro: DP\&A, 2005.

HOBSBAWM, E. Tempos Fraturados: cultura e sociedade no século XX. São Paulo: Companhia das Letras, 2013.

KUPER, A. Cultura: a visão dos antropólogos. Bauru: EDUSC, 2002. 
LUKÁCS, G. Velha e Nova Cultura. 1978, [s. p.]. Arquivo Marxista na Internet. Disponível em: <http://www.marxists.org/portugues/lukacs/1920/ mes/cultura.htm>. Acesso em: 18 nov. 2014.

MACIEL-LIMA, S. M.; SOUZA-LIMA, J. E. de. O sujeito pós-moderno no debate cultural contemporâneo. Polis: Revista de la Universidad Bolivariana, v. 9, n. 27, p. 199-217, 2010. Disponível em: <http://www.scielo.cl/pdf/polis/v9n27/art09. pdf $>$. Acesso em: 2 dez. 2016.

MARX, K.; ENGELS, F. A ideologia alemã. Tradução Luís Cláudio de Castro e Costa. 3. ed. São Paulo: Martins Fontes, 2007.

MORAES, L. A. S. S. Identidade do adolescente na contemporaneidade: contribuições da escola. TransFormações em Psicologia, São Paulo, v. 2, n. 1, p. 86-98, 2009. Disponível em: <http://pepsic. bvsalud.org/pdf/transpsi/v2n1/a06.pdf>. Acesso em: 2 dez. 2016.

MORRISON, T. Beloved. New Yok: Alfred. A. Knopf, 1987. Disponível em: <https://ymerleksi. wikispaces.com/file/view/Toni+Morrison++Beloved+(gnv64).pdf>. Acesso em: 18 nov. 2014.
Amada. São Paulo: Companhia das Letras, 2007.

ORTIZ, R. A Escola de Frankfurt e a questão da cultura. [1986]. Portal das Ciências Sociais Brasileiras. [s. p.]. Disponível em: $<$ http://www. anpocs.org.br/portal/publicacoes/rbcs_00_01/ rbcs01_05.htm>. Acesso em: 18 nov. 2014.

TEIXEIRA, D. R.; DIAS, F. B. M. Marxismo e Cultura: contraponto às perspectivas pósmodernas. Filosofia e Educação, Campinas, v. 2, n. 2, p. 120-140, out. 2010/mar. 2011. Disponível em: <http://www.fe.unicamp.br/revistas/ged/rfe/ article/view/2164/2033>. Acesso em: 19 nov. 2014.

VEIGA-NETO, A. Cultura, Culturas e Educação. Revista Brasileira de Educação, Rio de Janeiro, n. 23, p. 5-15, maio/ago. 2003. Disponível em: $<$ http://www.scielo.br/pdf/rbedu/n23/n23a01.pdf $>$. Acesso em: 18 nov. 2014.

WEBER, M. A ética protestante e o espírito do capitalismo. 6. reimpr. São Paulo: Companhia das Letras, 2004. 